\title{
How large are the differences between originator and generic prices? Analysis of five molecules in 16 European countries
}

\section{Sabine Vogler ${ }^{1}$}

Head of Pharma Team, Head of WHO Collaborating Centre for Pharmaceutical Pricing and Reimbursement Policies, Wien, Austria

\begin{abstract}
OBJECTIVE: To survey the price differences between originators and generics for a selected basket of molecules and to analyze similarities and differences with regard to the countries included and their generic policies. METHODS: Ex-factory prices as of November 2011 of five molecules provided from the Pharma Price Information (PPI) service of the Austrian Health Institute were analyzed for 16 European countries (Austria, Belgium, Denmark, Finland, France, Germany, Greece, Ireland, Italy, the Netherlands, Norway, Portugal, Spain, Switzerland, Sweden, UK). The selected molecules were gemcitabine, mycophenolate mofetil, olanzapine, risperidone and sumatriptan. For a specific presentation (same pack size, dosage and pharmaceutical form) of each molecule, the prices of the original product and the "most common generic" as defined by PPI were compared. RESULTS: Considerable variations among the extent of price differences between originator and generic were identified (gemicitabine: lowest price difference of $1.4 \%$ between originator and generic in Belgium and highest difference of $73.4 \%$ in Portugal; mycophenolate mofetil: $3.4 \%$ Norway $-71.7 \%$ Netherlands; olanzapine: $0.1 \%$ Spain - 97.1\% Sweden; risperidone: $0.9 \%$ Netherlands - 97.3\% UK; sumatriptan: 5.8\% Greece - 95.0\% Denmark). Further, no difference at all between originator and generic prices was found for some molecules in a few countries (Norway: for 4 of the 5 molecules analyzed; Spain: 3; Belgium: 2; in Austria, France and Greece for one molecule respectively). For the five molecules of the sample, Greece, Spain, Ireland and Norway consistently displayed lower price differences whereas Denmark, Finland and Sweden tended to show higher differences between originator and generic prices. CONCLUSION: Even if this research is illustrative and not representative due to the small sample size, results suggest confirming large differences across Europe. It appears that countries (e.g. Denmark, Sweden) with strong generic policies, particularly based on competition and involving elements of enforcement, tend to have higher differences between originator and generic prices. Further research, notably with a broader basket, is recommended.
\end{abstract}

\section{Keywords}

Generic policies; Medicines prices; Pricing; Price difference; Europe; Competition; Regulation

\section{INTRODUCTION}

A generic medicine is a pharmaceutical product which has the same qualitative and quantitative composition in active substances and the same pharmaceutical form as the reference original medicine, and whose bioequivalence with the reference medicine has been demonstrated by appropriate bioavailability studies [1]. Generics are launched when the patent of the originator product has expired. Whereas the quality of generics is with no difference to the one of original products, they tend to be cheaper: the European Generics Medicines Association indicates generic prices being 20 to 90 percent lower than those of original medicines [2].
Therefore, generics are seen as a major policy option for cost-containment since, due to their lower prices, they benefit the health care systems by providing savings which might be used for funding innovation. An international study covering 17 countries worldwide found out that cost savings of more than 50 percent could be generated in all but two of 17 studied countries surveyed if consumption shifted from the originator brand product to the lowest-priced generic equivalent available at medicine outlets in the private sector [3]. A study on generic policies on seven OECD countries (European countries, US, Canada) published in 2008 estimated that significant additional savings to health insurances of up
Corresponding author Dr. Sabine Vogler Sabine.Vogler@goeg.at

\section{Disclosure}

The author has no financial conflict of interest to declare 
to $43 \%$ of current generic sales could be realized if generic purchasing and genericisation improved further [4]. For Europe, while the European Generics Medicines Association estimated overall savings for EU patients and health care systems of over 25 billion Euro each year [5]; further data were provided by studies analyzing the impact of specific policies: An Austrian study as of 2008 estimated yearly savings for the social health insurance of up to 55 million Euro in case of the implementation of a reference price system (i.e. reimbursement of a defined amount for identical or similar products in a cluster) and generic substitution (i.e. the pharmacist dispensing a generic instead of the prescribed brand original product); these savings would correspond to ten percent of total pharmaceutical expenditure in Austria [6]. Another study assessed the reductions in public expenditure on original products due to generic substitution as of 20 to 50 percent for selected European countries [7]. Following patent expiries in recent years and expected further expiries [8] future savings can be expected to be considerably higher than estimated in these studies performed some years ago.

Due to the potential of generics for patients and health systems to achieve equivalent health outcomes at a lower cost, measures to promote generics uptake have been implemented by several European countries: they include both supply-side measures such as a linkage of pricing and/or reimbursement decisions on generics to the originator medicines, tendering mechanisms and accelerated procedures regarding pricing and/or reimbursement decisions and demand-side measures such as prescribing by the International NonProprietary Name (INN), monitoring prescribing behaviour, pharmaceutical budgets and generics substitution [9-14]. Reference price systems accompanied by either INN prescribing or generic prescribing tend to be common instruments to promote generics uptake (18 of the European Union Member States); only one EU Member State (Austria) implemented none of these three measures [15]. At the supply side, the "generic price link", i.e. setting the price of a generic medicine at a specific rate below the originator price, is also a common feature in shaping generic policies $[9,13,15]$. In current economically difficult times, generic policies are considered as a policy option to further develop even though they are not - such as price reductions and co-payments - the top emergency measures in response to the global financial crisis [16]. Generic medicines prices have been surveyed and analyzed in international price comparisons, both at global and European level [17-
21]. The extent of the differences between the prices of generics and original medicines was surveyed in fewer studies. One important report in this respect is the Pharmaceutical Sector Inquiry 2009 of the European Commission: it showed that in 17 EU Member States generics enter the market at on average a price slightly under $80 \%$ of the originator's price. After three years the prices of both the originator and the generics dropped on average to about $75 \%$ and $55 \%$ respectively of the originator's price at generic entry [22]. The study design of the Pharmaceutical Sector Inquiry, an analysis of relative prices, was challenged, and concern was expressed that the reasons for the variability and the potential role and interplay of regulation and competition were not sufficiently investigated [23]. This study particularly aims to survey the extent of the price differences between generic and original medicines and compare them across European countries. Price differences for a basket of selected molecules among European countries are analyzed, and a possible relationship to the generic prices, generics market shares and generic policies will be explored.

\section{METHODS}

A basket of five molecules whose patent had already expired was selected for the analysis. The selected medicines are applied in different indications. Included in the analysis were: gemcitabine (an anti-neoplatic agent), mycophenolate mofetil (immunosuppressant), olanzapine (anti-depressant), risperidone (anti-psychotic) and sumatriptan (analgetic).

The price survey and analysis was undertaken for 16 European countries, some of them being major pharmaceutical markets: Austria, Belgium, Denmark, Finland, France, Germany, Greece, Ireland, Italy, the Netherlands, Norway, Portugal, Spain, Switzerland, Sweden, and the UK.

Data were provided by the Pharma Price Information (PPI) service of the Austrian Health Institute [24]. The PPI service is an information service which offers medicine prices of the EU Member States covering all price types. It was established to support, according the Austrian General Social Insurance Law [25], the Austrian Pricing Committee located at the Austrian Federal Ministry of Health which calculates the EU average price which is needed for price setting since Austria applies external price referencing and sets its prices based on the average prices of the prices in all other EU Member States [26]. Data of the PPI service are provided 
at request to all interested parties and might also be requested for research.

Prices were analyzed at the ex-factory price level, since the issue of distribution margins was not scope of this study. Data were provided as of November 2011. Price data from non-Euro countries were converted into Euro based on the monthly exchange rate of the European Central Bank as of November 2011. A pair of a specific original product and an identical generic was subject to the analysis, thus comparing presentations in the same pack size, dosage and pharmaceutical form. In determining the identical presentation the author was guided by the Defined Daily Dosis (DDD) as stipulated by the WHO Collaborating Centre for Drug Statistics Methodology in Oslo, and checked a larger PPI data set to identify pairs of originator and generic medicines available in several countries.

For some of the selected presentations, generics from more than one supplier were offered - sometimes, but not always - with the same price. Included into the analysis were those generics which the PPI service had defined as the "most common generic". Suppliers of the most common generic might differ among the countries.

Prices and price differences were analyzed at unit price level. The prices were calculated per DDD because for the given research question a unit price analysis served better the purpose to understand pricing strategies. Furthermore, two of the molecules selected had no DDD allocated due to their highly individualized use, and applying country specific DDDs would have distorted the analysis.

In some cases data on the original product and the corresponding generic in the defined presentation were not available because products, usually the generic versions, were not marketed in these pack sizes, dosages and/or pharmaceutical forms. In order to achieve high data coverage, the following exemptions for the pairs analyzed were accepted: different but similar pack sizes (e.g. 30 units instead of 28 units) were included in the analysis. Deviations to the pharmaceutical form were rarely permitted, only in the case of film-coated tablets, tablets and capsules. Similar strengths (e.g. $6 \mathrm{mg}$ instead of $4 \mathrm{mg}$ ) were accepted in very few cases. While these variances were allowed among the countries analyzed, the pair of an original product and its comparable generic per country needed to have the identical pack size, dosage and pharmaceutical form (one exemption: olanzapine, the Netherlands). Despite these exemptions data had to be excluded in some countries because no generic corresponding to the originator was on the market.

Table I provides an overview about the five analyzed molecules including methodologi-

\begin{tabular}{|c|c|c|c|c|}
\hline Molecule & Indication & $\begin{array}{l}\text { Defined daily } \\
\text { dose (DDD)* }\end{array}$ & $\begin{array}{c}\text { Selected } \\
\text { presentation }\end{array}$ & Comments \\
\hline Gemcitabine & $\begin{array}{l}\text { Breast cancer, } \\
\text { anti-neoplastic } \\
\text { agent }\end{array}$ & No DDD defined & $\begin{array}{l}1 \text { vial containing } \\
1 \mathrm{~g} \text { powder } \\
\text { for solution for } \\
\text { infusion }\end{array}$ & $\begin{array}{l}\text { Comparable data available for } 12 \text { countries. } \\
\text { No price comparison possible in } \mathrm{DE}, \mathrm{ES}, \mathrm{IE} \text {, } \\
\text { SE due to missing generics in a comparable } \\
\text { presentation }\end{array}$ \\
\hline $\begin{array}{l}\text { Mypcophenolate } \\
\text { mofetil }\end{array}$ & Immunosuppressant & No DDD defined & 100 caps 250 mg & $\begin{array}{l}\text { Comparable data available for } 16 \text { countries. AT: } \\
\text { different pack size and dosage (150 } 500 \mathrm{mg} \text { f/c } \\
\text { tabs), BE, CH, DK: } 300 \text { units, but same dosage } \\
\text { and pharmaceutical form }\end{array}$ \\
\hline Olanzapine & $\begin{array}{l}\text { Schizophrenia, } \\
\text { anti-depressant }\end{array}$ & $10 \mathrm{mg}$ & $28 \mathrm{f} / \mathrm{c}$ tabs $10 \mathrm{mg}$ & $\begin{array}{l}\text { Comparable data available for } 13 \text { countries. } \\
\text { No price comparison possible in } \mathrm{CH} \text {, DE, } \\
\text { DK due to missing generics in a comparable } \\
\text { presentation. NL: data adjusted at unit level - } \\
30 \text { units/pack for original product, } 28 \text { units/pack } \\
\text { for generic, NO: different pharmaceutical form: } \\
\text { orodispersible tabs, SE: } 56 \text { units, same dosage } \\
\text { and pharmaceutical form }\end{array}$ \\
\hline Risperidone & $\begin{array}{l}\text { Schizophrenia, } \\
\text { anti-psychotic }\end{array}$ & $5 \mathrm{mg}$ & $60 \mathrm{f} / \mathrm{c}$ tabs $4 \mathrm{mg}$ & Comparable data available for 16 countries \\
\hline Sumatriptan & $\begin{array}{l}\text { Migraine, analgetic, } \\
\text { SS antagonist }\end{array}$ & $50 \mathrm{mg}$ (oral) & $6 \mathrm{f} / \mathrm{c}$ tabs $50 \mathrm{~g}$ & $\begin{array}{l}\text { Comparable data available for } 11 \text { countries. } \\
\text { No price comparison possible in AT, FI, FR, IT, } \\
\text { SE due to missing generics in a comparable } \\
\text { presentation ES and EL: } 4 \text { units, PT: } 2 \text { units, } \\
\text { same pack size and pharmaceutical form; BE: } \\
100 \text { mg f/c tabs }\end{array}$ \\
\hline
\end{tabular}

Table I. Molecules analyzed and limitations regarding comparability* as defined by the WHO Collaborating Centre for Drug Statistics Methodology, Oslo [27]

$\mathrm{AT}=$ Austria; $\mathrm{BE}=$ Belgium; $\mathrm{CH}=$ Switzerland; $\mathrm{DE}=$ Germany; $\mathrm{DK}=$ Denmark; $\mathrm{EL}=$ Greece; $\mathrm{ES}=\mathrm{Spain} ; \mathrm{FI}=\mathrm{Finland} ; \mathrm{IE}=\mathrm{Ireland}$; IT = Italy; $\mathrm{NO}=$ Norway; $\mathrm{SE}=$ Sweden 
cal comments on the selected presentations for the analysis.

Price differences were defined and calculated as the percentage which the generic medicine is cheaper than the original product. A possible correlation between the generics market and generic policies respectively and the extent of the price differences was investiga-

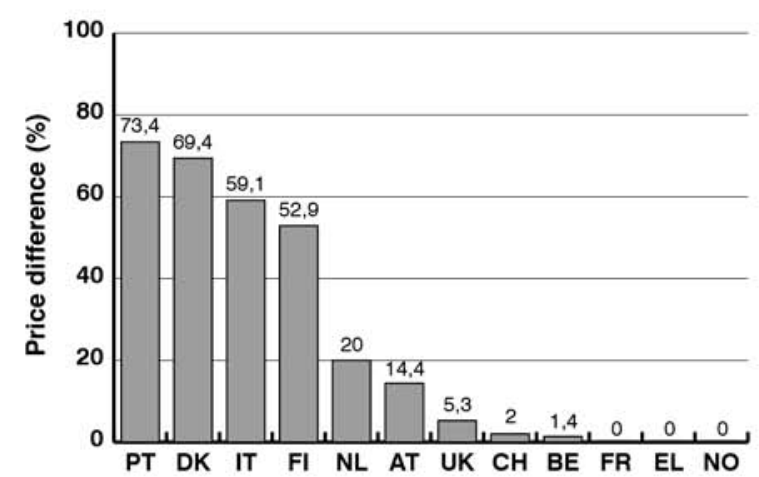

Gemcitabine, 1 vial $1 \mathrm{~g}$ powder

for solution for infusion $(n=12)$

No price comparison possible in DE, ES, IE, SE due

to missing generics in a comparable presentation

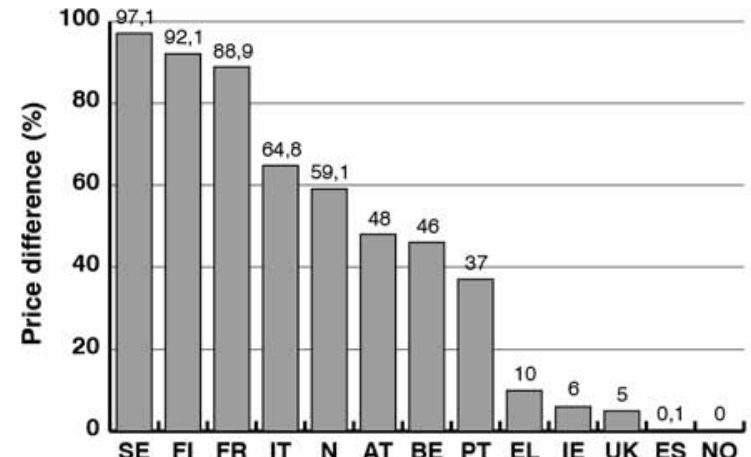

Olanzapine, $28 \mathrm{f} / \mathrm{c}$ tabs $10 \mathrm{mg}(\mathrm{n}=13)$

$\mathrm{NL}$ : data adjusted at unit level -30 units/pack for original product, 28 units/pack for generic, NO: different

pharmaceutical form: orodispersible tabs, SE: 56 units, same dosage and pharmaceutical form

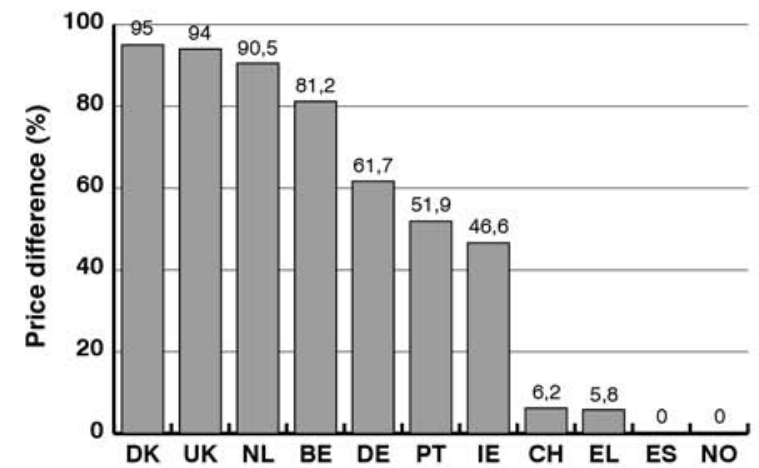

Sumatriptan, $6 \mathrm{f} / \mathrm{c}$ tabs $50 \mathrm{~g}(\mathrm{n}=11)$

ES and EL: 4 units; PT: 2 units, same pack size and pharmaceutical form; BE: $100 \mathrm{mg} f / \mathrm{c}$ tabs

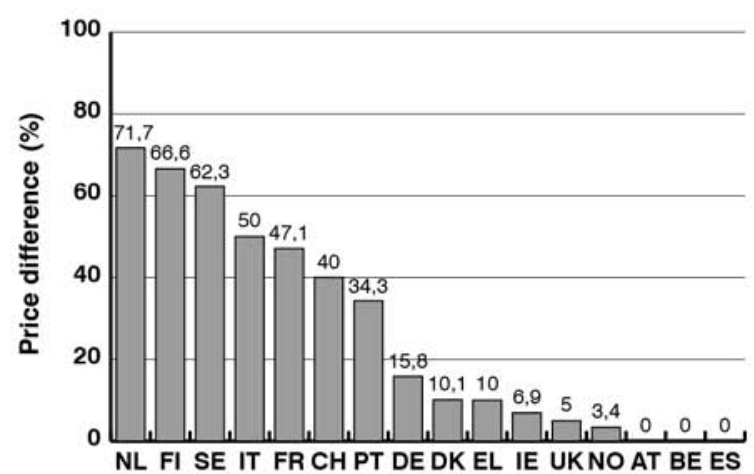

Mypcophenolate mofetil, 100 caps $250 \mathrm{mg}(\mathrm{n}=16)$ AT: different pack size and dosage (150 $500 \mathrm{mg} \mathrm{f} / \mathrm{c}$ tabs), $\mathrm{BE}, \mathrm{CH}, \mathrm{DK}: 300$ units, but same dosage and pharmaceutical form

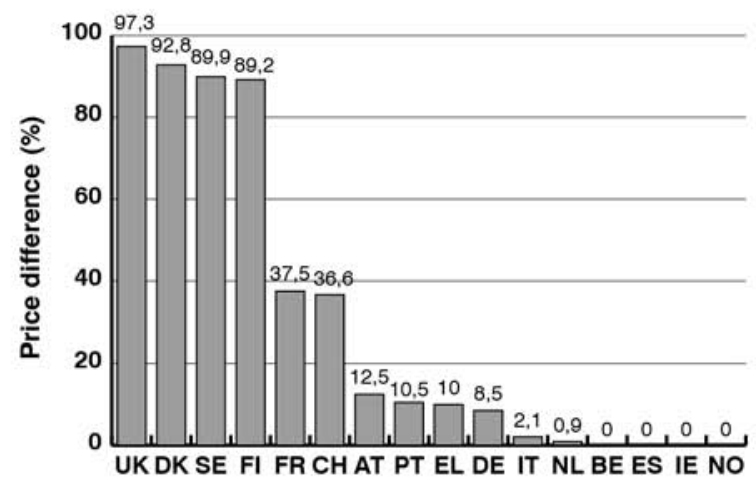

Risperidone, $60 \mathrm{t} / \mathrm{c}$ tabs $4 \mathrm{mg}(\mathrm{n}=16)$

Figure 1. Price differences (expressed as the percentage which the price of the generic is lower than the one of the originator) between identical presentations of the originator and generic for five molecules in 16 European countries, data as of November 2011

$\mathrm{AT}=$ Austria; $\mathrm{BE}=$ Belgium; $\mathrm{CH}=$ Switzerland; $\mathrm{DE}=$ Germany; $\mathrm{DK}=$ Denmark; $\mathrm{EL}=$ Greece; $\mathrm{ES}=\mathrm{Spain} ; \mathrm{FI}=$ Finland; $\mathrm{FR}=\mathrm{France} ; \mathrm{IE}=\mathrm{Ireland} ; \mathrm{IT}=$ Italy; NL = the Netherlands; $\mathrm{NO}=$ Norway; PT = Portugal; SE =Sweden; UK = United Kingdom 
ted. Information about generic policies and the generics market was provided by PPRI (Pharmaceutical Pricing and Reimbursement Information) network members. PPRI is a networking and information-sharing initiative on pharmaceutical policies from a public health perspective which emerged from a European Commission co-funded project under the same name $[28,29]$. As in June 2012, PPRI consisted of nearly 70 institutions, mainly Medicines Agencies, Ministries of Health and Social Insurance institutions, from 40 countries, including all $27 \mathrm{EU}$ Member States, plus European and international institutions (European Commission services and agencies, OECD, WHO and World Bank). PPRI network members provide on a regular basis information and data about pharmaceutical policy measures and outcome indicators to the PPRI secretariat which collects and manages these data in the socalled PHIS (Pharmaceutical Health Information System) database [30]. Though the indicators are published in an annually updated version in the Internet, for this manuscript the internal version of the PHIS database was consulted in order to obtain, wherever possible, information and data as of November 2011. While the quality as well as coverage of data on policy measures are accurate due to regular contact and requests to the PPRI members, the data quality regarding the generics market shares is limited since authorities in some countries do not have exact and up-to-date data. The author therefore validated these data by consulting published data from the European Generics Association (EGA) which refer to the market shares as of 2006 [31]. Apart from Finland (low generics market share in the EGA data) no major inconsistency was detected.

\section{RESULTS}

The price differences between the originator and the equivalent generic medicine of the five selected molecules varied among the fifteen countries: from $1.4 \%$ (Belgium) to 73.4\% (Portugal) for gemicitabine (comparable data available for 12 countries), from $3.4 \%$ (Norway) to $71.7 \%$ (the Netherlands) for mycophenolate mofetil (16 countries), from $0.1 \%$ (Spain) to $97.1 \%$ (Sweden) for olanzapine (13 countries), $0.9 \%$ (the Netherlands) to $97.3 \%$ (UK) for risperidone (16 countries) and from $5.8 \%$ (Greece) to $95.0 \%$ (Denmark) for sumatriptan (11 countries). Additionally, for all five molecules analyzed there was at least one country where the price of the generic was identical to the one of the original product (gemicitabine: 3 countries, mycophenolate mofetil: 3 countries, olanzapine: 1 country, risperidone: 4 countries, sumatriptan: 2 countries) (Figure 1).

Expressed in absolute figures, the prices per pack of generics were lower as of $€ 134.77$ (Denmark) to $€ 0.85$ (Belgium) for gemicitabine (no price difference in France, Greece and Norway); of $€ 190.73$ (Switzerland) to $€ 1.72$ (Norway) for mycophenolate mofetil (no difference in Austria, Belgium and Spain); of $€ 77.49$ (Finland) to $€ 0.04$ (Spain) for olanzapine (no difference in Norway); of $€ 95.35$ (United Kingdom) to $€ 0.82$ (Italy) for risperidone (no difference in Belgium, Ireland, Norway and Spain); and of $€ 45.04$ (Belgium) to $€ 0.39$ (Greece) for sumatriptan (no difference in Norway and Spain).

Since the unit prices for the medicines analyzed were, apart for gemicitabine, usually less than four Euro, the unit price differences in Euro were accordingly low. Figure 2 explored the possible relationship between the extent of the price differences and generic price. Some limited pattern is visible in a few countries: for instance, Norway and, to some extent also Ireland, tended to have comparably higher prices and low or even no price differences between the originator and the generic. At the other end, Sweden, Finland and Denmark ranked low regarding generic prices of the studied medicines but had, as a trend, differences of more than $70 \%$, and sometimes $90 \%$, between the originator and the generic prices. A similar picture was seen in the United Kingdom and the Netherlands, however in a less consistent way than in the three Nordic countries.

No correlation was found between the extent of the price difference and the relevance of the generics market, expressed in the outpatient generics market share in volume (Figure 3). While countries with an advanced generics market such as Finland and Sweden displayed in some cases higher price differences, this is not the case for Germany and Norway. On the other hand, Portugal, with a rather lower generics market share, displayed price differences of some relevance.

Table II provides an overview of the "classical" policy measures with regard to generic promotion for the countries analyzed which were clustered into ones with apparently high and low price differences. All three countries with high price differences (Denmark, Sweden and Finland) did not link the prices of generics to the ones of originators, while the countries identified to have low or no price differences (Belgium, Greece, Norway, Spain) did so. Countries with high price differences tended to have generic substitution introduced on a mandatory basis. 


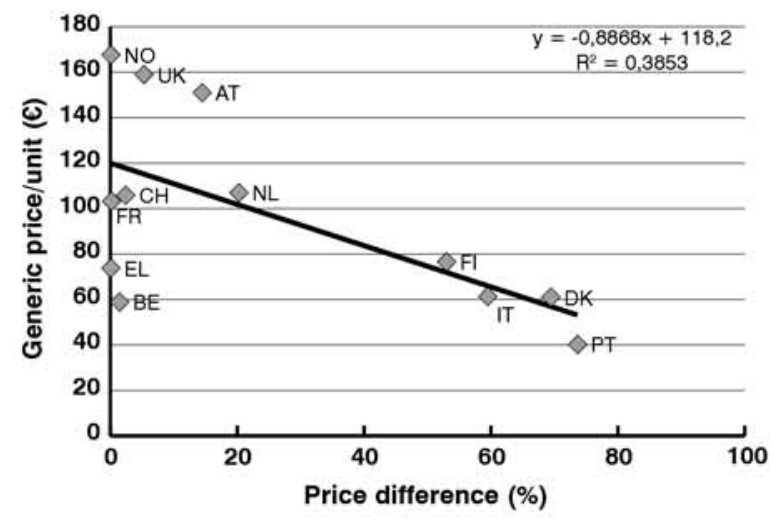

Gemcitabine, 1 vial $1 \mathrm{~g}$ powder

for solution for infusion $(n=12)$

No price comparison possible in DE, ES, IE, SE due

to missing generics in a comparable presentation

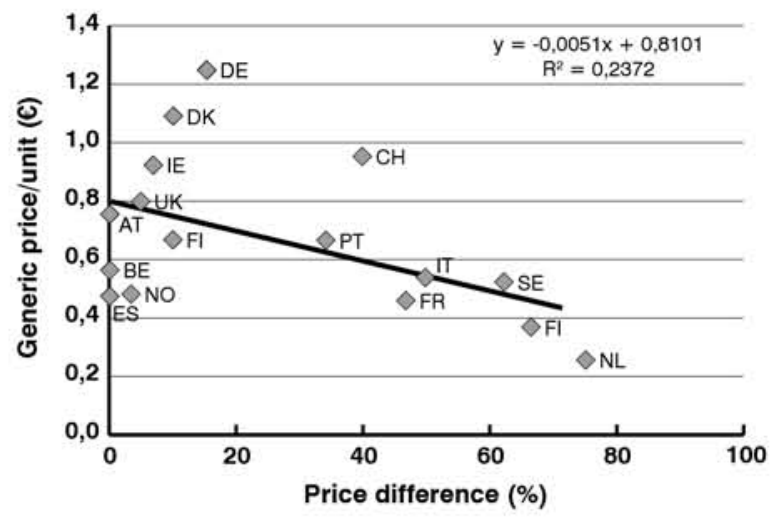

Mypcophenolate mofetil, 100 caps $250 \mathbf{~ m g ~}(n=16)$ AT: different pack size and dosage (150 $500 \mathrm{mg} \mathrm{t} / \mathrm{c} \mathrm{tabs}$ ), $\mathrm{BE}, \mathrm{CH}, \mathrm{DK}: 300$ units, but same dosage and pharmaceutical form

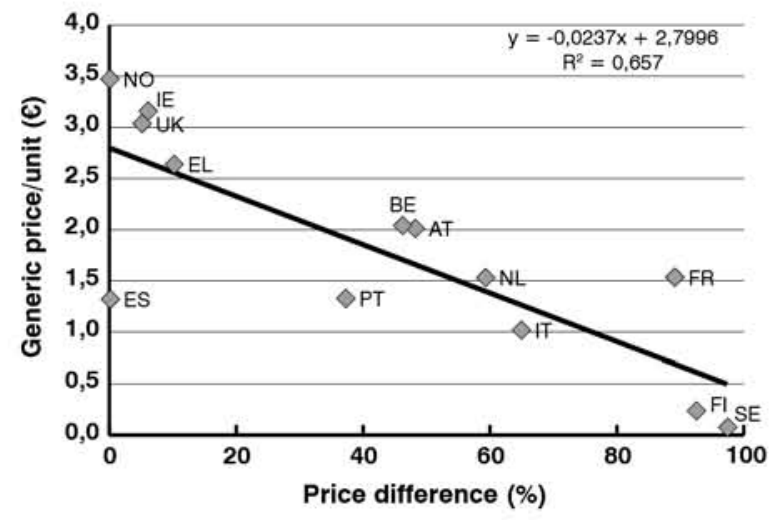

Olanzapine, $28 \mathrm{f} / \mathrm{c}$ tabs $10 \mathrm{mg}(\mathrm{n}=13)$

NL: data adjusted at unit level -30 units/pack for original product, 28 units/pack for generic; NO: different

pharmaceutical form: orodispersible tabs; SE: 56 units, same dosage and pharmaceutical form
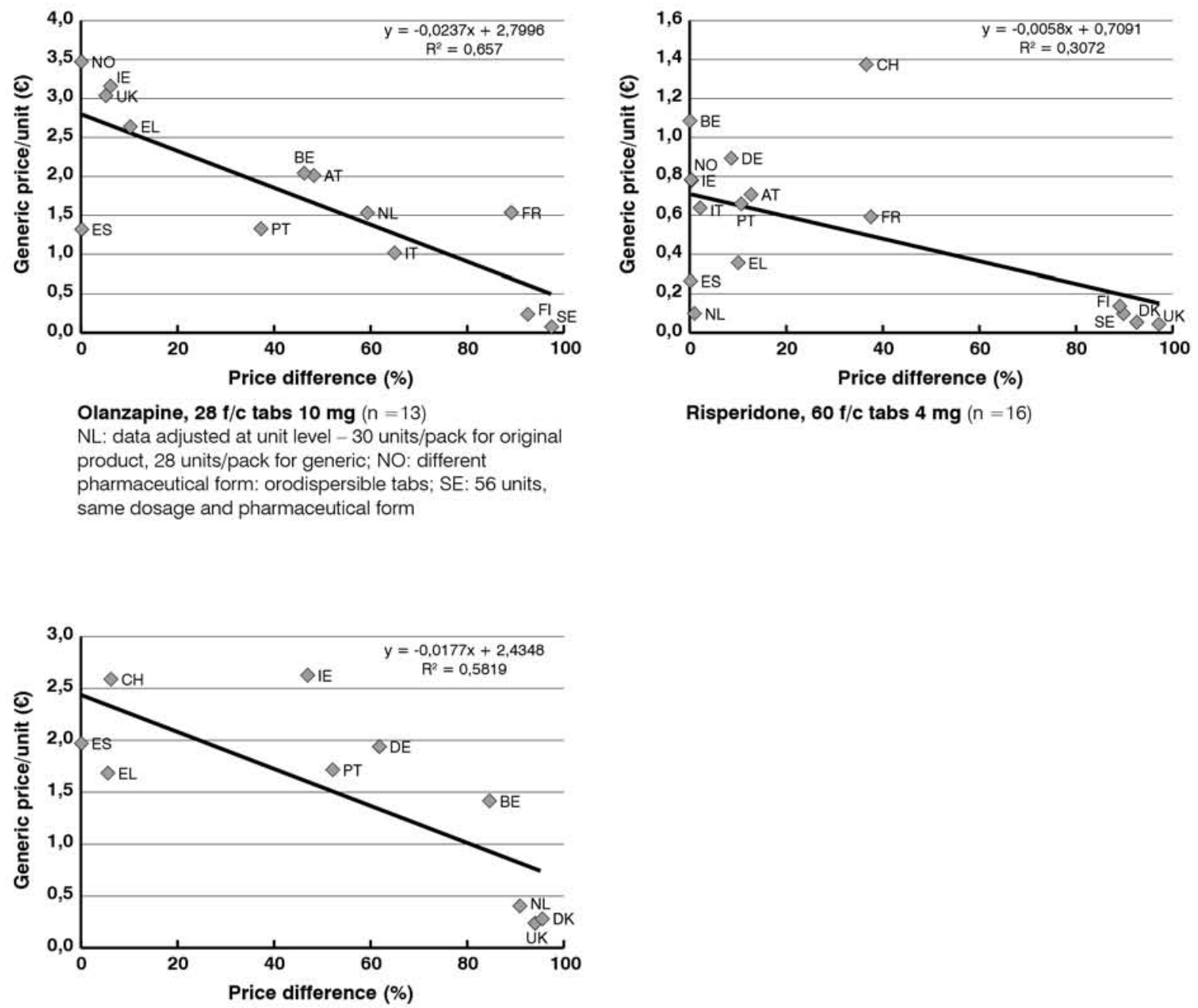

Risperidone, $60 \mathrm{f} / \mathrm{c}$ tabs $4 \mathrm{mg}(\mathrm{n}=16)$

Sumatriptan, $6 \mathrm{f} / \mathrm{c}$ tabs $50 \mathrm{~g}(\mathrm{n}=11)$

ES and EL: 4 units; PT: 2 units, same pack size and pharmaceutical form; $\mathrm{BE}: 100 \mathrm{mg} \mathrm{f} / \mathrm{c}$ tabs

Figure 2. Price differences (expressed as the percentage which the price of the generic is lower than the one of the originator) between identical presentations of the originator and generic and the prices of the generic medicine per unit for five molecules in 16 European countries, data as of November 2011

$\mathrm{AT}=$ Austria; $\mathrm{BE}=$ Belgium; $\mathrm{CH}=$ Switzerland; $\mathrm{DE}=$ Germany; $\mathrm{DK}=$ Denmark; $\mathrm{EL}=$ Greece; $\mathrm{ES}=\mathrm{Spain} ; \mathrm{FI}=$ Finland; $\mathrm{FR}=\mathrm{France} ; \mathrm{IE}=\mathrm{Ireland} ; \mathrm{IT}=$ Italy; NL = the Netherlands; NO = Norway; PT = Portugal; SE =Sweden; UK = United Kingdom 


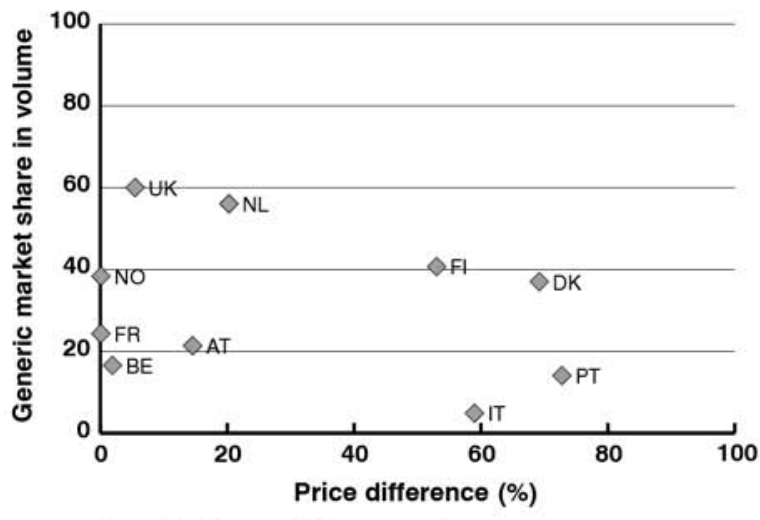

Gemcitabine, 1 vial $1 \mathrm{~g}$ powder for solution for infusion $(n=10)$

No price comparison possible in DE, ES, IE, SE due to missing generics in a comparable presentation

Market share data missing for $\mathrm{CH}$, EL, IE; further notes on generics market shares see below

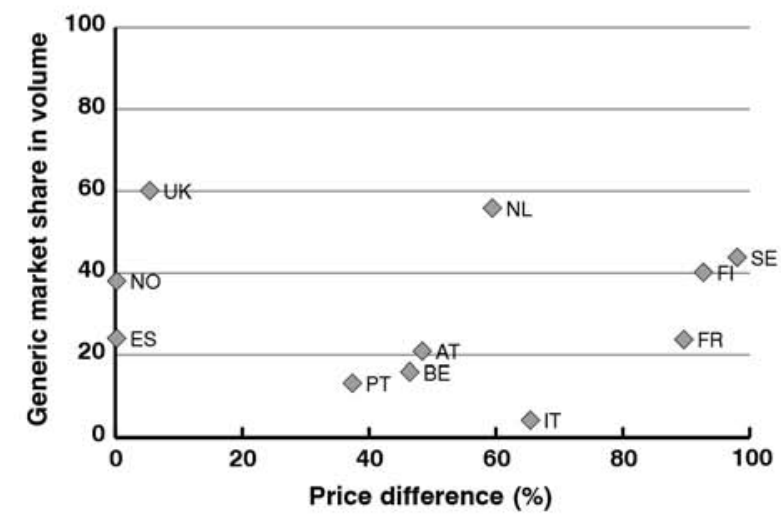

Olanzapine, $28 \mathrm{t} / \mathrm{c}$ tabs $10 \mathrm{mg}(\mathrm{n}=11)$

NL: data adjusted at unit level: 30 units/pack for original product, 28 units/pack for generic; NO: different pharmaceutical form: orodispersible tabs; SE: 56 units, same dosage and pharmaceutical form

Market share data missing for $\mathrm{CH}, \mathrm{EL}, \mathrm{IE}$; further notes on generics market shares see below

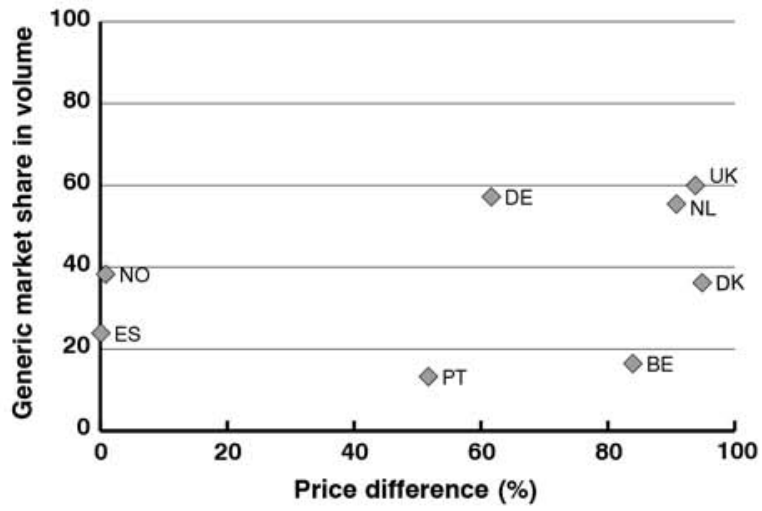

Sumatriptan, $6 \mathrm{f} / \mathrm{c}$ tabs $\mathbf{5 0} \mathrm{g}(\mathrm{n}=11)$

ES and EL: 4 units; PT: 2 units, same pack size and

pharmaceutical form; BE: $100 \mathrm{mg} / / \mathrm{c}$ tabs

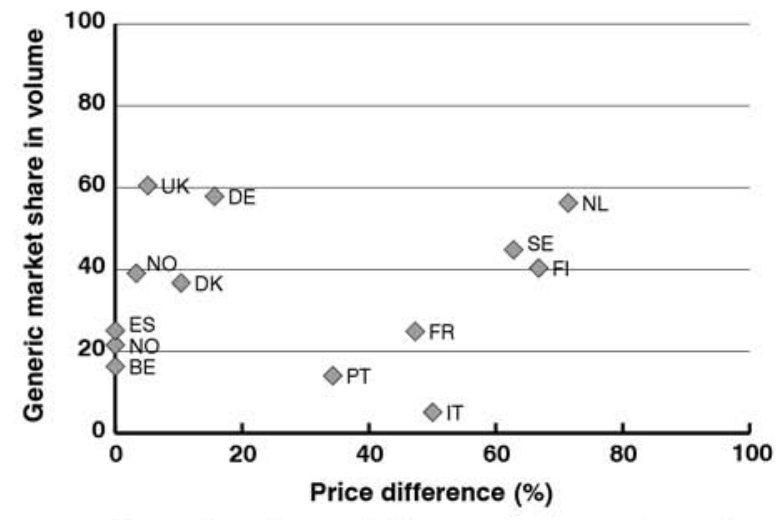

Mypcophenolate mofetil, 100 caps $\mathbf{2 5 0} \mathbf{~ m g ~ ( ~} \mathrm{n}=12$ ) AT: different pack size and dosage (150 $500 \mathrm{mg} \mathrm{f} / \mathrm{c} \mathrm{tabs}$ ), $\mathrm{BE}, \mathrm{CH}, \mathrm{DK}: 300$ units, but same dosage and pharmaceutical form

Market share data missing for $\mathrm{CH}$, EL, IE; further notes on generics market shares see below

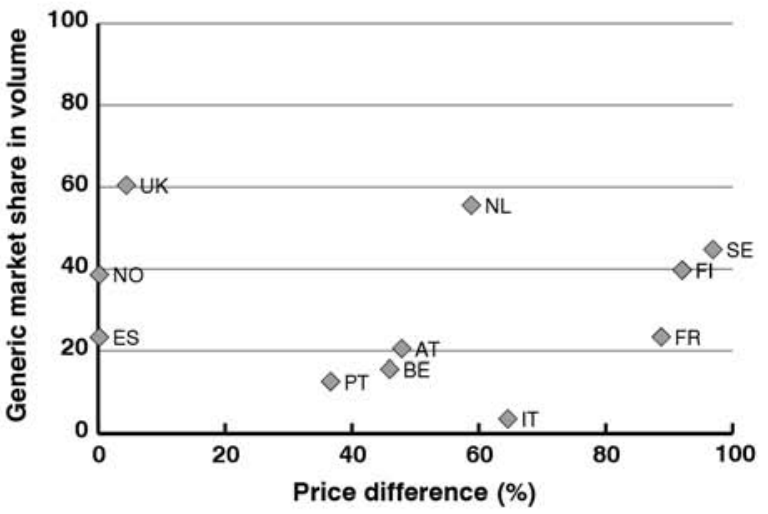

Risperidone, $\mathbf{6 0} \mathrm{f} / \mathrm{c}$ tabs $\mathbf{4} \mathbf{m g}(\mathrm{n}=13)$

Market share data missing for $\mathrm{CH}$, EL, IE; further notes on generics market shares see below

Figure 3. Price difference (expressed as the percentage which the price of the generic is lower than the one of the originator, price data as of November 2011) between identical presentations of the originator and generic for five molecules and generics market shares * in 16 European countries

* generics market share in volume in the out-patient sector. No data available for $\mathrm{CH}, \mathrm{EL}, \mathrm{IE}$. Note on generics market shares: $2004=\mathrm{IT}, 2005=\mathrm{DE}$, $2006=\mathrm{SE}, 2007=\mathrm{AT}, \mathrm{NO} ; 2008=\mathrm{FI}, 2010=\mathrm{BE} ;$ out-patient reimbursed sector $=\mathrm{ES}$

$\mathrm{AT}=$ Austria; $\mathrm{BE}=$ Belgium; $\mathrm{CH}=$ Switzerland; $\mathrm{DE}=$ Germany; $\mathrm{DK}=$ Denmark; $\mathrm{EL}=$ Greece; $\mathrm{ES}=\mathrm{Spain} ; \mathrm{FI}=$ Finland; $\mathrm{FR}=\mathrm{France} ; \mathrm{IE}=\mathrm{Ireland}$; $\mathrm{IT}=$ Italy; NL = the Netherlands; NO = Norway; PT = Portugal; $\mathrm{SE}=$ Sweden; UK = United Kingdom 


\begin{tabular}{|c|c|c|c|c|}
\hline Country & Generic price link & Reference price system & Generic substitution & INN prescribing \\
\hline \multicolumn{5}{|c|}{ Countries with high price differences between originator and generic } \\
\hline Denmark & No & RPS at ATC 5 & Yes, mandatory & Yes, indicative \\
\hline Finland & No & RPS at ATC 5 & Yes, mandatory & Yes, indicative \\
\hline Sweden & No & No & Yes, mandatory & Not allowed \\
\hline \multicolumn{5}{|c|}{$\begin{array}{l}\text { Countries with moderate price differences between originator and generic } \\
\text { and/or no clear picture for the studied molecules }\end{array}$} \\
\hline Austria & Yes & No & Not allowed & Not allowed \\
\hline Germany & No & RPS with broad clusters & Yes, mandatory & Yes, indicative \\
\hline France & Yes & RPS at ATC 5 & Yes, indicative & Yes, indicative \\
\hline Ireland & Yes & No & Not allowed & Yes, indicative \\
\hline Italy & Yes & RPS at ATC 5 & Yes, indicative & Yes, indicative \\
\hline Netherlands & No & RPS with broad clusters & Yes, indicative & Yes, indicative \\
\hline Portugal & Yes & RPS at ATC 5 & Yes, indicative & Yes, mandatory \\
\hline Switzerland & N.a. & No & Yes, indicative & No \\
\hline United Kingdom & No & No & Not allowed & $\begin{array}{l}\text { Yes, indicative and } \\
\text { highly encouraged }\end{array}$ \\
\hline \multicolumn{5}{|c|}{ Countries with low price differences between originator and generic } \\
\hline Belgium & Yes & RPS at ATC 5 & Not allowed* & Yes, indicative \\
\hline Greece & Yes & PRS at ATC 5 & Not allowed & Yes, indicative \\
\hline Norway & Yes & RPS at ATC 5 & Yes, indicative & Yes, indicative \\
\hline Spain & Yes & RPS at ATC 5 & Yes, indicative & Yes, mandatory \\
\hline
\end{tabular}

Table II. Generic policy measures in the countries analyzed, clustered with regard to their extent of differences between originator and generic prices, as in November 2011

* Not allowed at the time to which the prices refer to (November 2011). Since 1 April 2012, every prescription of an antibiotic or antifungal medicine is regarded as a prescription by INN and the pharmacist is obliged to dispense the lowest priced medicine

ATC $=$ Anatomic Therapeutic Chemical classification system by WHO; ATC $5=$ defines a single active ingredient or a fixed combination of active ingredients within the ATC classification system, i.e. RPS is based on the same active ingredients; INN = International Non-Proprietary Name;

RPS = Reference Price System

\section{DISCUSSION}

Despite of the limitation of a rather small basket of molecules analyzed, some pattern among the studied countries can be observed. Some countries had consistently no or little price differences between the originator and the generic product, while others displayed price differences ranging from 50 to up to nearly 100 percent for the molecules analyzed: Belgium, Greece, Norway and Spain ranked at the lower end for most of the molecules analyzed. There appears to be a need for improved generic promotion in Belgium, Greece and Spain since generics market shares are rather low (Figure 3). While policy measures to promote generics uptake are in place in these countries (Table II), they have apparently not been fully exploited: for instance, generic substitution and/or INN promotion have been implemented on an indicative basis and not in a mandatory way, and the percentage rate defined in the generic price link policy appears comparably low. In Belgium, while the reference price system has stimulated the generics market and has led to a reduction of the originator prices as well, the possible role of prescribers and pharmacists in enhancing generics uptake were not sufficiently considered [32]. In Spain, generic policies are seen as an important policy option, and the country introduced some changes with the summer 2011 reform package which included speeding up of the establishment of reference groups in the reference price system, a change in the methodology in generic substitution allowing a broader use and making INN prescribing mandatory [33]. Greece has been criticized for long - not only for the missing implementation of a consistent generic promotion policy but also, in general, for the lack of a sustainable health care and pharmaceutical policy [34-36].

It is a rather surprising result that Norway showed no price difference for four of the five molecules and only a minor one for the fifth. This also contradicted evidence about the country's low generic prices resulting from its active generic policies. Norway has been promoting generics primarily via the "stepped price model" (Trinnprismodellen) which provides incremental price decreases according to pre-defined rates, depending on sales volu- 
mes. The first reduction occurs after a medicine has lost patent protection [37]. The "stepped price model" was considered accountable for increasing the generics market shares and lowering generic prices $[37,38]$. The hypothesis that the non-existing or low price differences might be a result from already existing low generic prices, as a study about the overall market suggests [21], could not be confirmed for the molecules of this analysis: the prices of the selected generics usually ranked in the upper field (Figure 2). While further research on this issue is, in general, encouraged, it would be particularly of interest to study in further depth generics prices in Norway.

The other Nordic states Sweden, Denmark and also Finland were among those countries showing the highest price differences between the originator and an equivalent presentation of the generic medicine. Generic markets in these countries are advanced (Figure 3 ), and generic policies are predominantly based on competition. Denmark is one of the few European countries which applies tendering procedures in the out-patient sector: every two weeks, the reference product (i.e. the one reimbursed) under the reference price system is tendered for, and only the "winner" will be reimbursed [6,39]. While the high frequency of the change certainly implies logistical challenges, in particular for pharmacies - and initial problems indeed occurred leading to shortages resulting in the National Health Service having to pay for higher priced available medicines [6] -, the tendering system creates a highly competitive market environment. As one of the first European countries Sweden implemented a reference price system in 1993 but abolished it in 2002. Nonetheless, within the system for generic substitution substitutable medicines are grouped together, and a price which is lower or the same as the highest price within a group of substitutable medicine is accepted without further investigation. This policy measure is supplemented by mandatory generic substitution. Experts from Sweden attribute savings in pharmaceutical expenditure to their generic policies, especially to the mandatory generic substitution [10]. A lesson learned from the Swedish action could be that policy measures should not just be implemented somehow but they need to be enforced. Enforcement appears to be particularly relevant for generic substitution and INN prescribing since countries having introduced these measures in a mandatory way tend to have higher generics uptake than those with indicative generic substitution and/or INN prescribing [15]. While INN prescribing and/or generic substitution is still implemen- ted in an indicative way in most European countries (see Table II), in recent times some countries decided on a policy change by making INN prescribing mandatory, generally or at least for some products (e.g. Lithuania in June 2010, Spain in August 2011, Slovakia in December 2011 and recently Hungary for statins in April 2012). Finland introduced a reference price system in 2009 - this was at a time when many other European countries already had one. Even before the implementation of the reference price system, Finland had an advanced generics market and could generate savings from generics. This was attributable to generic substitution which triggered price competition [40]. The reference price system further enhanced generic competition and drove prices down [41].

The picture on the Netherlands and the UK is far less clear because high price differences were displayed for some molecules whereas the differences were moderate and even low for others (Figure 1). Both the Netherlands and the UK have a strong generics market (Figure 3), and they have been promoting generics for a long time though they chose different approaches. The Netherlands introduced a reference price system in the early 1990s and an electronic system to convert brand prescriptions into INN prescriptions and awarded for years (till 2004) a financial incentive to pharmacists in return for generic substitution $[6,7,10,42]$. During the last years the so-called preference price policy for selected molecules has been applied. The Dutch preference price policy is, like in Denmark, a tendering procedure in the out-patient sector [43]. With this policy health insurance companies determine one or a limited number of medicine(s) per cluster (medicines with the same active ingredient, dosage form and strength) as preferred, each time for a fixed period of usually six months. The preferred medicine winning the tender will be reimbursed [44]. In terms of savings the preference price policy was considered as very successful; initial total savings (projected to $€$ 355 million annually) exceeded expectations since the preference policy scheme resulted in fierce price competition among generic companies [45]. From the molecules studied in this analysis, olanzapine, risperidone and sumatriptan typically fall under the preference price policy [46]. For these products, the differences between originator and generic prices are often quite low, and generic prices are also at a low level (Figure 2). Apparently price competition involved not only the generics under the preference price system but also the originator, and data suggest confirming analyses which highlight considerable 
price reductions for the molecules under the preference price policy [47].

The UK contributes its high generics market shares to INN prescribing which is not mandatory but highly encouraged. It has neither a reference price system nor generic substitution; the government decided against the introduction of generic substitution planned for 2010 following a public consultation [15]. For the five molecules studied, high price differences (more than 90\%) were identified in case of only two molecules, and for those the generic prices were low as well. For the other molecules analyzed, however, the differences were moderate and even low, and generic prices ranked in the middle and upper field (Figure 2). Studies criticized that the British National Health Service paid too high generic prices in the UK $[48,49]$.

The situation appears similar for Germany for which results are only available for three molecules: Germany is known for a strong competitive generics market, based on a reference price system which provides broad reference groups in which even original products may be clustered as alternatives [6], and it has an advanced generics market (Figure 3). But the extent of the price differences was rather low, and generic prices were in the middle and upper field. This is in line with other price comparisons in Europe which showed rather high generic prices [20,21] and high originator prices in Germany [21]. Given the broad use of external price referencing in the nearly all other European countries, pharmaceutical industry was incentivized to first launch a medicine in Germany because, till recently, the country had a free pricing policy [50]. Having said that about Germany's high price level, it should be reminded that the prices of medicines which are reimbursed by sickness funds are in fact lower due to discount agreements with the sickness funds [51-53].

Last but not least, Portugal deserves some discussion. Portugal has been working for more than a decade on promoting its generics market $[6,54,55]$, but it has not always achieved the results envisaged. Till 2010, the generics market share in value used to be higher than the one in volume [56] which is an indication of excess generic prices. For years Portugal had defined the reference price equivalent to the highest priced generic in the reference group [15]. In 2010 policy makers decided to reset the price to the average of the five lowest priced medicines, and, also in response to the global financial crisis, strengthened its efforts on enforcing generics policies [16]. As the results illustrate, with regard to the price differences Portugal ranks middle (in the one case of gemcitabine it even displays the highest price difference amounting to more than $70 \%$ ), and generic prices of the selected molecules are in the lower and middle field among the sixteen countries analyzed.

Whereas the discussion of the results at a country per country basis allows lessons to be learned about successful and less successful approaches in enhancing generics uptake, no correlations could be found at an overall level: It could neither be proven that countries with high price differences had consistently low generic prices nor that high price differences were a feature of advanced generic markets. This corresponds to results of a study investigating the relationship between generics market shares and the change of generic prices over time: It identified different extents of price decreases in the low and high generics market share countries [57].

While price data from the PPI service are considered as of good quality, and the information on policy measures is up-dated and should be as complete as possible, limitations regarding the generics market share do exist. Though based on a common definition, data on generics market shares were provided by country representatives from competent authorities and not by the market players, and they might include some inconsistencies with regard to the definition. Additionally, some generics market share data do not refer to 2009 but to previous years. The author considered taking the generics market shares provided by the European Generics Association, but decided against it since published information dates back to the year 2006 .

The extent of the price differences might also be impacted by the different time periods which had passed since patent expiry. However, since the author had no access to the exact patent expiry dates of the molecules of the study, such analysis could not be performed. Another limitation is the rather small sample of products. The limited size of the sample is also due to the fact that it was hard to identify identical - or at least comparable presentations of the originator and the generic product in a reasonable number of countries. The author initially checked a sample of a total of 22 medicines with a generic alternative in at least one country derived from the PPI service. For the reasons described in the methodology section only five molecules were eligible for the analysis. With the on-going expiry of patents the analysis might be repeated in future with a broader product sample.

\section{CONCLUSIONS}

Even if this research is illustrative and not representative due to the small sample, the 
study allows drawing some tentative conclusions. The results suggest some pattern for the European countries. Countries with strong generic policies (e.g. Denmark, Sweden), based on competition and involving enforcement (e.g. mandatory generic substitution and/or INN prescribing), tend to have higher differences between originator and generic prices and lower generic prices. Other high generics market countries such as the UK, the Netherlands or Germany did not necessarily show considerable price differences, nor did their generic prices rank in the lower field. The study results confirm that investments in generic policies tend to pay off. However, as the country examples highlighted, it is not sufficient to launch generic policies to enhance generic competition but the measures should be carefully designed and should involve elements of enforcement as well as monitoring and evaluation. Policy makers are encouraged to reconsider existing generic policies and to reflect on their design and implementation.

Further research is recommended. In particular, with the expiry of further patents the study should be repeated with a broader basket of products.

\section{ACKNOWLEDGEMENTS}

I would like to deeply thank my colleagues from the Austrian Health Institute who work for the PPI (Pharmaceutical Price Information) service for providing the price data used in this analysis. In particular, I would like to convey my thanks to Claudia Habl, Florian Bachner and Bettina Schmickl for their extensive work on the price data compilation which was a valuable asset and prerequisite for doing the analysis. I am grateful to Escra Coskun, Ingrid Freiberger, Patricia de Groot, Joy Ladurner, Christine Leopold, Klaus Kellner, Judith Oberdammer, Daniela Pertl, Günter Sprinzl and Nina Zimmermann; together with Claudia Habl, Florian Bachner and Bettina Schmickl they did an excellent job to collect price data in the 16 countries. Furthermore, I highly appreciate the commitment and activities of the members of PPRI (Pharmaceutical Pricing and Reimbursement Information) network. For this paper, I could draw from their regularly provided information about the pharmaceutical policy measures and the generics market shares. Finally, I thank my colleague Nina Zimmermann for the maintenance of the PHIS database and the regular updates.

\section{REFERENCES}

1. WHO Collaborating Centre for Pharmaceutical Pricing and Reimbursement Policies. Glossary of pharmaceutical terms. Latest update of print version: 2011; regularly updated online. Vienna 2011. Available at: http://whocc.goeg. at/Glossary/Search [Accessed: June 20, 2012]

2. European Generics Association (EGA). Frequently Asked Questions about Generic Medicines. 2012. Available at: http://www.egagenerics.com/FAQ-generics.htm [Accessed 24 June 2012]

3. Cameron A, Laing R. Cost savings of switching private sector consumption from originator brand medicines to generic equivalents. World Health Report, Background Paper, 35. Geneva, 2010

4. Seeley E, Kanavos P. Generic medicines from a societal perspective: savings for health care systems? Eurohealth 2008;14: 18-21

5. European Generics Association (EGA). EGA Fact Sheet. 2012. Available at: http://www.egagenerics.com/doc/ ega_factsheet-01.pdf [Accessed 15 June 2012]

6. Habl C, Vogler S, Leopold C, et al. Referenzpreissysteme in Europa. Analyse und Umsetzungsvoraussetzungen für Österreich. Wien: ÖBIG Forschungs- und Planungsgesellschaft mbH; 2008

7. Simoens S, De Coster S. Sustaining generic medicines markets in Europe. Journal of Generic Medicines 2006; 3 : 257-68; http://dx.doi.org/10.1057/palgrave.jgm.4940128

8. Sheppard A (ed.). Generic medicines: essential contributors to the long term health of society. Sector sustainability challenges in Europe. Global Generics, Thought Leadership. Presentation. Brussels, 25 March 2010

9. Simoens S. A review of generic medicine pricing in Europe. GaBI Journal 2012; 1: 8-12

10. Vogler S, Habl C, Leopold C, et al. PPRI Report. Vienna: Gesundheit Österreich GmbH / Geschäftsbereich ÖBIG, 2008

11. Vogler S, Habl C, Bogut M, et al. Comparing pharmaceutical pricing and reimbursement policies in Croatia to the European Union Member States. Croat Med J 2011; 52: 183-97

12. Garattini L, Tediosi F. A comparative analysis of generics markets in five European countries. Health Policy 2000; 51: 149-62; http://dx.doi.org/10.1016/S0168-8510(00)00061-0 
13. Puig-Junoy J. Impact of European pharmaceutical price regulation on generic price competition: a review. PharmacoEconomics 2010; 28: 649-63; http://dx.doi.org/10.2165/11535360-000000000-00000

14. Espin J, Rovira J. Analysis of differences and commonalities in pricing and reimbursement systems in Europe. Brussels: Andalusian School of Public Health; Commissioned by the European Commission, Directorate-General Enterprise 2007

15. Vogler S. The impact of pharmaceutical pricing and reimbursement policies on generics uptake: implementation of policy options on generics in 29 European countries - an overview. GaBI Journal 2012; 1: 93-100

16. Vogler S, Zimmermann N, Leopold C, et al. Pharmaceutical policies in European countries in response to the global financial crisis. Southern Med Review 2011; 4: 32; http://dx.doi.org/10.5655/smr.v4i2.1004

17. Cameron A, Ewen M, Ross-Degnan D, et al. Medicine prices, availability, and affordability in 36 developing and middle-income countries: a secondary analysis. The Lancet 2009; 373: 240-9; http://dx.doi.org/10.1016/S01406736(08)61762-6

18. Danzon PM, Chao LW. Cross-national price differences for pharmaceuticals: how large, and why? J Health Econ 2000; 19: 159-95

19. Danzon PM, Furukawa MF. Prices and availability of pharmaceuticals: evidence from nine countries. Health Affairs 2003; 22: W521- W536

20. Simoens S. International comparison of generic medicine prices. Curr Med Res Opin 2007; 23: 2647-54; http:// dx.doi.org/10.1185/030079907X233395

21. Brekke KR, Holmås TH, Straume OR. Are pharmaceuticals still inexpensive in Norway? A comparison of prescription drug prices in ten European countries. SNF report no. 08/10. Bergen, 2010

22. European Commission Competition Directorate-General. Pharmaceutical sector inquiry final report. Brussels: 2009

23. Leopold C, Rovira J, Habl C. Generics in small markets or for low volume medicines European Union. Vienna: EMINet, 2010

24. Pharma Price Information (PPI) service. Available fromat www.goeg.at/en/PPI: Gesundheit Österreich GmbH (Austrian Health Institute); 2012.

25. General Social Insurance Act $§ 351 c$, Federal Law No. 189/1955, latest change by Federal Law I No. $398 / 2011$ [in German], 2012

26. Bundesministerium für Gesundheit. Regelung für die Vorgehensweise der Preiskommission bei der Ermittlung des EU-Durchschnittspreises gemäß $\S 351$ c Abs. 6 ASVG. 1 January 2008

27. WHO Collaborating Centre for Drug Statistics Methodology. ATC/DDD Index 2012, searchable version on the Web. Oslo, 2012. Available from: http://www.whocc.no/atc_ddd_index/ [Accessed 10 June 2012]

28. Arts D, Habl C, Rosian I, Vogler S. Pharmaceutical Pricing and Reimbursement Information (PPRI): a European Union project. Italian Journal of Public Health 2006; 3: 41

29. Vogler S, Espin J, Habl C. Pharmaceutical Pricing and Reimbursement Information (PPRI) - New PPRI analysis including Spain. Pharmaceuticals Policy and Law 2009; 11: 213-34

30. WHO Collaborating Centre for Pharmaceutical Pricing and Reimbursement Policies. PHIS Database. Vienna: Pharmaceutical Health Information System (PHIS), 2011. Available from: http://phis.goeg.at/index.aspx?alias=phisDatabase

31. European Generics Association (EGA). The Use of Generic Medicines in Europe. Facts and Figures from EGA on generics market shares and the healthcare gap. Brussels, 2007

32. Simoens S, Kristien De B, Bogaert M, et al. Pharmaceutical Policy regarding Generic Drugs in Belgium. PharmacoEconomics 2005; 23: 755-66; http://dx.doi.org/10.2165/00019053-200523080-00002

33. Martínez Vallejo M, Ferré de la Peña P, Guilló Izquierdo MJ, et al. PHIS Pharma Profile Spain 2010. Vienna: Pharmaceutical Health Information System (PHIS); Commissioned by the European Commission, Executive Agency for Health and Consumers and the Austrian Federal Ministry of Health 2011

34. Mossialos E, Allin S, Davaki K. Analysing the Greek health system: a tale of fragmentation and inertia. Health Economics 2005; 14(S1): S151-S68; http://dx.doi.org/10.1002/hec.1033

35. Contiades X, Golna C, Souliotis K. Pharmaceutical regulation in Greece at the crossroad of change: Economic, political and constitutional considerations for a new regulatory paradigm. Health Policy 2007; 82: 116-29; http:// dx.doi.org/10.1016/j.healthpol.2006.09.003

36. Tsiantou V, Zavras D, Kousoulakou H, et al. Generic medicines: Greek physicians' perceptions and prescribing 
practices. J Clin Pharm Ther 2009; 34: 547-54; http://dx.doi.org/10.1111/j.1365-2710.2009.01037.x

37. Festøy H, Yu LM. PHIS Pharma Profile Norway 2011. Vienna: Pharmaceutical Health Information System (PHIS); Commissioned by the European Commission, Executive Agency for Health and Consumers and the Austrian Federal Ministry of Health, 2011

38. Håkonsen H, Horn AM, Toverud EL. Price control as a strategy for pharmaceutical cost containment—What has been achieved in Norway in the period 1994-2004? Health Policy 2009; 90: 277-85; http://dx.doi.org/10.1016/j. healthpol.2008.09.018

39. Leopold C, Habl C, Vogler S,et al. Steuerung des Arzneimittelverbrauchs am Beispiel Dänemark. Vienna: Gesundheit Österreich GmbH (Austrian Health Institute), 2008

40. Aalto-Setälä V. The impact of generic substitution on price competition in Finland. The European Journal of Health Economics 2008; 9: 185-91; http://dx.doi.org/10.1007/s10198-007-0059-0

41. Koskinen H. Measuring and comparing pharmaceutical expenditures - Considerations based on national and European experiences. Drug Utilisation and Health Policy meeting "Better public health through pharmaco-epidemiology and quality use of medicine"; Antwerp: EuroDURG / ISPE 2011

42. Leopold C, Vogler S, Habl C. Was macht ein erfolgreiches Referenzpreissystem aus? Erfahrungen aus internationaler Sicht [in German] / Implementing a successful reference price system - Experiences from other countries. Soziale Sicherheit 2008: 614-23

43. Dylst P, Vulto A, Simoens S. Tendering for outpatient prescription pharmaceuticals: What can be learned from current practices in Europe? Health Policy 2011; 101: 146-52; http://dx.doi.org/10.1016/j.healthpol.2011.03.004

44. Zuidberg C. The pharmaceutical system of the Netherlands. A comparative analysis between the Dutch out-patient pharmaceutical system, in particular the pricing and reimbursement characteristics, and those of the other European Union Member States, with a special focus on tendering-like systems. Vienna: Gesundheit Österreich GmbH, 2010

45. Kanavos P, Seeley L, Vandoros S. Tender systems for outpatient pharmaceuticals in the European Union: Evidence from the Netherlands, Germany and Belgium. LSE Health, 2009

46. Data from three health insurers as of 2012: https://www.menzis.nl/web/Zorgaanbieders/Zorgsoorten/FarmaceutischeZorg/Contractering/Preferentiebeleid.htm, http:/www.cz.nl/lijst-voorkeursgeneesmiddelen/2012.pdf, http:// www.vgz.nl/sitecollectiondocuments/2012/d0201-vgz-reglement-farmaceutische-zorg.pdf, some variations among the health insurers.

47. Kanavos P. Tender systems for outpatient pharmaceuticals in the European Union: Evidence from the Netherlands and Germany. London: EMINET, January 2012 [Not published]

48. Kanavos P. Do generics offer significant savings to the UK National Health Service? Curr Med Res Opin 2007; 23: 105-16; http://dx.doi.org/10.1185/030079907X159506

49. Dylst P, Simoens S. Generic medicine pricing policies in Europe: current status and impact. Pharmaceuticals 2010; 3: 471-81; http://dx.doi.org/10.3390/ph3030471

50. Leopold C, Vogler S, Mantel-Teeuwisse AK, et al. Differences in external price referencing in Europe-A descriptive overview. Health Policy 2012; 104: 60

51. Dauben H-P, Stargardt T, Busse R. PPRI Pharma Profile Germany. Vienna: Gesundheit Österreich GmbH / Geschäftsbereich ÖBIG, 2008

52. Ognyanova D, Zentner A, Busse R. Pharmaceutical reform 2010 in Germany. Eurohealth 2011; 17: 11-3

53. Vogler S, Zimmermann N, Habl C, et al. Discounts and rebates granted to public payers for medicines in European countries. Southern Med Review 2012; 5: 38-46

54. Vogler S, Leopold C. Access to essential medicines in Portugal. Vienna: ÖBIG Forschungs- und Planungsgesellschaft mbH, 2009

55. Teixeira I, Vieira I. PPRI Pharma Profile. Portugal. Vienna: PPRI (Pharmaceutical Pricing and Reimbursement Information), 2008

56. Gomes M. Pricing and reimbursement policies in the light of the financial crisis. Country examples: Portugal. Presentation at the PPRI Conference. Vienna: PPRI (Pharmaceutical Pricing and Reimbursement Information); 2011; Available from: http://whocc.goeg.at/Downloads/Conference2011/PraesentationenPPRIKonferenz/Day1_afternoon_Festsaal_1300_Gomes.pdf

57. Dylst P, Simoens S. Does the market share of generic medicines influence the price level? An European analysis. PharmacoEconomics 2011; 29: 875-82; http://dx.doi.org/10.2165/11585970-000000000-00000 